\title{
The Application of PBL Teaching Method in the Teaching of Traditional Chinese Medicine Nursing
}

\author{
Yanping Du \\ School of Zhengzhou Industrial Technology, Medicine Department, Xinzheng, \\ Zhengzhou, Henan Province, China, 451150 \\ 464686281@qq.com
}

\section{Keywords: PBL; Teaching method; Traditional Chinese medicine; Nursing; Application}

\begin{abstract}
Objective: To compare the advantages and disadvantages of PBL teaching method and traditional teaching method in the teaching of traditional Chinese medicine nursing, and to explore the effective teaching methods of Chinese medicine nursing, so as to improve the teaching quality of traditional Chinese medicine nursing. Methods: Two classes of students majored in nursing were randomly selected into the observation group and the control group. Through a semester of teaching and completion of the PBL teaching method and the contents of the traditional teaching method, score analysis and questionnaire survey will be conducted at the end of the semester. Results: The statistical data were analyzed by SPSS16.0 statistical software. The scores of the students in the observation group were higher than those in the control group, and the differences were statistically significant $(\mathrm{P}<0.05)$. Conclusion: In Chinese medicine nursing teaching, the application of PBL teaching method can play an active role in improving the classroom teaching effect and teaching quality, as well as activating the classroom atmosphere and enhancing the enthusiasm and initiative of students' participation in class.

PBL is the abbreviation of problem based learning [1]. Compared with the traditional teaching method, in the teaching process, PBL has its own unique advantages. Specifically, it is a problem-based teaching method, emphasizing the main role of students, which is based on the problem, and teacher-oriented [2]. PBL is considered as a heuristic teaching model, and its teaching objectives focus on improving students' learning ability, as well as to initiate the students' learning enthusiasm and autonomy. In the implementation process, the basic links of PBL teaching method are: 1 . To organize a group 2 . To carry out new issues 3 . To solve the problem 4 . Reflection of the problem, etc. Medical disciplines have their own unique characteristics, and this teaching model matches the characteristics of medical disciplines. In particular, that is emphasized in the real problem of theory and clinical practice which must be combined.

This course can lay the foundation for other clinical subjects such as medical nursing, surgical nursing, obstetrics and gynecology nursing, pediatric nursing and so on[3]. This course can serve as a basis for the study of nursing specialty. The application of PBL teaching method in Chinese medicine nursing curriculum will help students to understand and master the knowledge, and this method is more advanced, but domestically used less for the course.

In foreign medical institutions PBL teaching method has been more applied, some domestic Chinese medicine institutions also try to use this teaching method[4]. And in the teaching practice PBL teaching method is deeply acknowledged as a kind of Medical education model and teaching methods in a kind of Medical education model and teaching methods in the Chinese medicine education reform[5]. From the year of 2011, we began the research of teaching method, try to apply it to traditional Chinese medicine nursing theory and experimental teaching, which aroused the students enthusiastic reaction. A better teaching effect can be seen in the performance analysis and questionnaire survey at the end of the semester. In short, it can better mobilize students' interest in learning and improve their academic performance.
\end{abstract}

\section{Research Objects and Methods}

Research Objects. Randomly selected a school class 2011 nursing class in a class (11 nursing 
specialist 2 classes) 64 people for the observation group, from the remaining traditional classes randomly selected a class (11 nursing specialist 4 classes) 64 for the control group. There were no significant differences in gender, age and enrollment scores between the two groups $(\mathrm{P}>0.05)$.

Methods. In the course of teaching Chinese medicine nursing, two groups of students were taught by the same teacher in the same class periods. Differently, the control group applied the traditional teaching methods for teaching, observation group applied PBL teaching method. Details are as follows:

Design of Issues. The design of problem is the foundation, and the teacher can design the problem according to the requirements of the syllabus. Duan Yaping and other scholars of the research report that the case is the core of PBL teaching method, the case (that is, the problem) must have the characteristics as follows: open-structured, true, able-to-explore, can lead to the field with the concept and can stimulate the students learning motivation [2]. So the questions are crucial and require high quality, for example comprehensive, enlightening and interesting.

Chinese medicine nursing is the basic course[6]. The teaching objects are the students who have no first basis of any medical foundation, and their clinical knowledge reserve is less than average. In this case, only by right of the life experience, it is rather difficult for the students to find out or raise any question according to the highlights of the course introduced by the teacher. At the same time, it has the tendency that the students do not know what to discuss without enthusiasm. So the teachers who teach Chinese medicine nursing are organized by the teaching and research section to discuss intensively so as to raise questions in groups according to the syllabus, teaching objectives, chapters of the content of the difficulties, the corresponding chapter of the knowledge points[7]. The final problem is roughly divided into three levels: primary, intermediate and advanced. Primary questions the most simple, and in the textbook, student will be able to find the correct answers, which generally belong to memory contents, such as what is called Zheng card? What is the etiology and pathogenesis of asthma syndrome? Basically, the concept of various diseases, clinical manifestations, etiology and pathogenesis, syndrome analysis, basic treatment methods and other content; intermediate problem is to be combined with textbooks, according to their own understanding of the content, students need to read the relevant information or papers or online Query the relevant information to be able to solve the problem, such as ovarian cysts of the latest research results or advanced treatment methods, such issues require teachers to guide, mainly to expand the knowledge-based; senior issues for clinical common, but not on the textbook Of the disease, through a variety of ways to collect information, including the hospital departments or related ward, through doctors, nurses, patients, cases and other means to collect clinical data, and ultimately the formation of papers and other results, published in the official journals[8].

Specific Steps. (1) At the beginning of the school students randomly grouped, each group of 10 or so, up to no more than 15 people, members of a reasonable division of labor, respectively, as supporters, recorders, representatives of the role of the spokesman; (2) Given the case, the group Students were discussed, a reasonable division of labor. Put forward the issues to be resolved, decide to refer to the information, books, limited to understand the scope of knowledge.(3) On the basis of the above groups to collect information, access to relevant literature, the formation of information; (4) Groups to fully study and discussion, the results in the classroom focus on the report, the classmates to discuss the classroom, the group were sent to representatives of the report The results of the group, in the process can be described in the collection of information encountered in the difficult problems, and the group of students can allow to add, other groups of students can free questions or comments, in order to discuss the normal, this step should pay attention to order; (5) Regardless of which process, teachers should pay attention to highlight the student's dominant position, pay attention to cultivate students' creative thinking, guide them to ask questions, solve the problem, (6) After discussion, teachers to sum up, should focus on the discussion process encountered Difficult and doubtful questions, the advantages of the students to praise, the mistakes occurred in the process to point out, and proposed amendments[9].

Teaching Effectiveness Assessment Means. The evaluation of the teaching effect is carried out from two groups of students studying the growth of interest and the grasp of theoretical knowledge 
in two aspects[10]. The mastery of the theoretical knowledge is mainly to carry out the examination papers, the observation group and the control group by the teachers for a unified proposition, the same time examination, the same teacher to read; learning interest growth is mainly statistical student questionnaire. Using the form of the questionnaire, the two teaching methods to evaluate.

\section{Findings}

Comparison of the Average Score of Two Groups of Students. The average score of the observation group was better than that of the control group, the difference was statistically significant $(\mathrm{P}<0.05)$. See Table 1

Table 1 Comparison of the average score of the two groups of students

\begin{tabular}{|l|l|l|l|l|}
\hline Group & Number & $\begin{array}{l}\text { Multiple choice } \\
\text { questions (50 points) }\end{array}$ & $\begin{array}{l}\text { Short answer } \\
\text { questions (30 points) }\end{array}$ & $\begin{array}{l}\text { Case analysis } \\
\text { questions (20 points) }\end{array}$ \\
\hline $\begin{array}{l}\text { Observation } \\
\text { group }\end{array}$ & 64 & $40 \pm 6.5$ & $22 \pm 6.5$ & $15 \pm 6.2$ \\
\hline Control group & 64 & $38 \pm 4.5$ & $19 \pm 6.4$ & $11 \pm 5.3$ \\
\hline
\end{tabular}

\section{The Students in the Observation Group of PBL Comprehensive Evaluation, See Table 2.}

Table 2 Students in the observation group PBL teaching method of comprehensive evaluation

\begin{tabular}{|c|c|c|c|c|c|c|c|c|}
\hline \multirow[t]{2}{*}{ Investigate the project } & \multicolumn{2}{|c|}{$\begin{array}{l}\text { Very } \\
\text { recognized }\end{array}$} & \multicolumn{2}{|c|}{ Recognized } & \multicolumn{2}{|c|}{ Uncertain } & \multicolumn{2}{|l|}{ Denied } \\
\hline & Number & $\%$ & Number & $\%$ & Number & $\%$ & Number & $\%$ \\
\hline Increased attention to lectures & 50 & 78 & 10 & 16 & 2 & 3 & 2 & 3 \\
\hline Learning to enhance the enthusiasm & 52 & 81 & 9 & 14 & 2 & 3 & 1 & 2 \\
\hline Increased Language Proficiency & 50 & 78 & 8 & 12 & 3 & 5 & 3 & 5 \\
\hline $\begin{array}{l}\text { To obtain a larger amount of } \\
\text { information }\end{array}$ & 55 & 86 & 8 & 12 & 1 & 2 & 0 & 0 \\
\hline $\begin{array}{l}\text { Better understanding of basic } \\
\text { knowledge }\end{array}$ & 55 & 86 & 4 & 6 & 3 & 5 & 2 & 3 \\
\hline
\end{tabular}

\section{Discussion}

Advantages of PBL Teaching Method. Although the PBL teaching method in nursing teaching of traditional Chinese medicine still in the process of accumulation of experience, the application has only just started, but has been fully shows the advantages, especially in the solution actual problem ability, and cultivate students' autonomous learning ability. Students, in the process of the research question, showed a very positive attitude, engaged in the problem, and to establish a strong sense of responsibility on learning tasks. According to Table 2, PBL teaching model compared with the traditional teaching model, students regardless of from the study enthusiasm, language power of expression, listening attention, or the analysis of the problem ability, etc., have obvious improvement.

In addition, the PBL method provides students with an active and relaxed learning environment. In the meantime, students not only speak freely, express their opinions fully, and listen to other people's opinions. but also receive the information collected by the group, and are generally well-rewarded. In the process of students to understand the understanding of theoretical knowledge has deepened, the basic knowledge of the memory capacity has also been improved, help to deepen the impression of learning, you can continue to discover new problems and solve new problems. In addition to this, you can also exercise the other aspects of the ability of students, such as improving 
the ability to access knowledge and summarize the ability to stimulate students' creative thinking potential, improve student communication, communication, cooperation, In the teacher of each student's personality and learning ability to comprehensively understand, do to teach.

\section{Existing Problems}

At present, in the implementation of PBL teaching, many problems need to be solved, mainly including: 1) PBL teaching method requires higher teaching materials, need to be matched with the preparation of teaching materials. 2) Students should actively adjust the learning state in time, from the perspective of their own, fulfill the role transformation, change from passive learners to learning master as soon as possible. Students should be left out of the "cramming" education and lack of learning initiative. 3) Students need to improve the computer skills in other courses, such as computer based courses. Because students struggle to use the Internet to collect data. 4) As an open teaching model, PBL teaching method has a high demand for teachers 'own quality and teachers' teaching skills, so Teachers need to pay attention to their own quality culture. 5) need to teachers, time, money, system and other aspects of protection, but also the need for school education and other functional departments of collaboration, especially in the teaching quality evaluation should focus on the actual evaluation of teaching effectiveness. In order to achieve better results in the reform teaching method, we need the active participation of schools, teachers, students and so on.

In the process of future teaching, the PBL teaching method will continue to be applied to the teaching of other courses, and will be continuously improved and enhanced, so that PBL teaching method will achieve better effects, make the greatest efforts to maximally meet the students' learning needs, and the teaching of the course will be lifted to a new level.

\section{References}

[1] Yume Jia, [J]. Journal of Henan College of Traditional Chinese Medicine, 2006,21 (01): 66-67. (In Chinese)

[2] W. Strunk Jr., E.B. White, The Elements of Style, third ed., Macmillan, New York, 1979.

[3] G.R. Mettam, L.B. Adams, How to prepare an electronic version of your article, in: B.S. Jones, R.Z. Smith (Eds.), Introduction to the Electronic Age, E-Publishing Inc., New York, 1999, p. 281-304.

[4] R.J. Ong, J.T. Dawley and P.G. Clem: submitted to Journal of Materials Research (2003)

[5] P.G. Clem, M. Rodriguez, J.A. Voigt and C.S. Ashley, U.S. Patent 6,231,666. (2001)

[6] Donnelly, R. 2006. Blended problem-based learning for teacher education: Lessons learnt learning. Media and Technology, 31(2), p. 93-116.

[7] European Commission: Annual Report on European SMEs 2013/2014: A Partial and Fragile Recovery.

[8] Hamburg, Mettam. 2014. Improving education and training impact on competitive advantages in SMEs. In: International journal of innovative research in electronics and communications (IJIREC) 1, no. 4, 54-60.

[9] Hamburg, Gaffar and O'Brien, E. 2014. Using strategic learning for achieving growth in SMEs. Journal of information technology and application in education 3(2), 77-83.

[10]Information on http:// www.umpblprep.nl/pbl-step-by-step 